\title{
ETNICIDADE NOS PAMPAS: A IDENTIDADE SOCIAL DO GAÚCHO
}

JULIA LANDGRAF ${ }^{1}$

UFRGS, BRASIL

https://orcid.org/0000-0002-2595-8771

\section{RESENHA}

LEAL, Ondina Fachel. Os gaúchos: cultura e identidade masculinas no pampa. Porto Alegre: Tomo Editorial, 2021 . p.368.

"Os gaúchos: cultura e identidade masculinas no pampa", foi escrito por Ondina Fachel Leal originalmente como tese de doutorado em Antropologia na Universidade da Califórnia (Berkeley) em 1989, e apenas agora, mais de três décadas depois, é traduzido ao português e publicado como livro. Essa publicação, tão posterior às incursões à campo que decorreram em sua elaboração analítica, evita a tentação de recompor-se em novas análises contemporâneas, mantendo seu formato original e encorpando-se com o acréscimo de material de campo, como canções e poemas (representativas da forte cultura oral dos gaúchos), que não haviam sido traduzidos ao inglês à oportunidade da tese. Tal acréscimo, conjuntamente com algumas belas imagens de autoria própria, ilustram as práticas sociais e os significados coletivos construídos conjuntamente nos galpões, espaços de autorreflexão do gaúcho aqui referido.

O livro divide-se em seis capítulos, ao longo dos quais serão abordadas as imagens ao redor desta identidade social ao longo do tempo e sua construção; aspectos específicos referentes ao trabalho de campo etnográfico e sua circunscrição; as narrativas realizadas pelos gaúchos a respeito de si mesmos nos galpões; a alteridade da mulher e a construção do homem a partir da ausência desta; questões de masculinidade e status

\footnotetext{
${ }^{1}$ Mestranda em Antropologia Social (Universidade Federal do Rio Grande do Sul, Brasil). E-mail: ferneda.julia@gmail.com
} 
ao redor das brigas de galos; e o suicídio enquanto morte social. Todas estas temáticas se organizam em torno da construção do que é essa identidade cultural do gaúcho, sua representação e a maneira como reverbera em distintas práticas sociais.

Portanto, quem é este gaúcho? Cabe explicitar aqui que "gaúcho" não é empregado referindo-se ao gentílico regional que aglutina a todos os sulriograndenses, mas o gaúcho "original": o peão campeiro, criador de animais no pampa, que engendra um modo de vida e identidade cultural específicos. Na centralidade deste livro, portanto, está entender o que é ser gaúcho, e quais as representações destes a respeito de si mesmos, em uma identidade social e étnica que acaba por amalgamar-se com uma identidade de gênero masculina. Cultura, identidade e gênero são categorias importantes propostas dentro dessa análise.

A autora propõe um recorrido histórico que demonstra como o surgimento desta identidade social está vinculada ao bioma do pampa e a abundância de cavalos na região. É possível que os grupos indígenas Minuanos e Charruas tenham sido os primeiros gaúchos - à cavalo, usando poncho e botas, domando cavalos com boleadeiras e à laço, ferramentas de trabalho do gaúcho até os dias de hoje. Ele incorpora características culturais luso-espanholas, devido à interação entre portugueses e espanhóis na região fronteiriça entre Brasil, Uruguai e Argentina, região de conquista e disputa dos limites territoriais. É importante ressaltar como a identidade gaúcha não se delimita por fronteiras dos Estados-nação, mas permeia a região pampeana destes três países. Se inicialmente (nos dois primeiros séculos de domínio português e espanhol) a região não era tão visada devido à corrida por metais preciosos, posteriormente torna-se mais interessante com a exploração do couro enquanto mercadoria, e os homens que trabalhavam com o gado passaram a ser vistos como vagabundos e fora da lei, pois a atividade (há muito realizada) se tornou monopólio do governo. Essa imagem de vago, errante, foi a primeira imagem do gaúcho. É a partir do século XX, também, que o trabalho assalariado finda a servidão e o trabalho de pessoas escravizadas no campo, trazendo outra dinâmica ao campo, mas reafirmando a identidade do gaúcho enquanto este trabalhador.

O consistente trabalho de campo realizado pela autora é demonstrativo também de parte das grandes contribuições que este livro tem a realizar ainda hoje, mais de 30 anos depois de sua publicação em formato de tese. A começar pelas imagens que traz como parte de suas pesquisas (também as anteriores à sua tese), que posteriormente a autora veio a nomear enquanto fotoetnografia - configurando, assim, um recurso bastante inovador à época e um marco na incorporação das imagens no trabalho antropológico no Brasil. Para além disso, a etnografia em questão foi realizada ao longo de dois anos, entre idas e vindas de Porto Alegre à Alegrete, região pampeana onde Leal encontrou a estância que a receberia. Tais fatores são dignos de consideração não apenas por seguir o "modelo clássico" de etnografia imersiva e persistente ao longo do tempo, mas também pelos caminhos metodológicos possíveis que são ofertados a quem lê, entre tratativas pela melhor forma de se inserir em campo e detalhes sobre a inserção de uma mulher em 
um campo tão masculino. Desde a percepção inicial de que a porta de entrada não poderia ser o vínculo com o patrão e a presença sempre dele acompanhada, o que não possibilitaria uma aproximação com os trabalhadores da estância, os gaúchos em questão, devido à hostilidade que permeia esta relação; até o estabelecimento de uma rede que a levou a um proprietário rural que disponibilizou sua estância para a permanência da autora, onde pouco a pouco forjou relações de cordialidade com os trabalhadores ali presentes. Sua inserção no galpão, espaço compartilhado pelos gaúchos após um longo dia de trabalho no campo e onde se criam os consensos sobre a realidade social através de canções, poemas, e o contar de causos, deu-se depois de travar contato individual com cada um deles, realizar entrevistas e ouvir suas histórias o que nos remete à questão imperiosa do tempo necessário para a inserção nesses espaços que constituem o cerne desta etnografia. O jogo entre permitir uma mulher em um espaço masculino, ao mesmo tempo que as conversas, piadas e causos contados eram selecionados; ou do uso de um vocabulário que não permitisse à etnógrafa imediatamente acessar o sentido das conversas fizeram parte do processo de decifrar o campo, em uma jornada lenta que acompanhamos ao imaginar a autora pouco a pouco ganhando espaço e confiança para ali transitar. Em outra publicação (LEAL, 1992), na qual temos acesso a um extrato de seu diário de campo de 1988, acompanhamos as estranhezas de ser uma mulher circulando sozinha na região do pampa (e não apenas o gaúcho e brasileiro, considerando que tal qual a identidade étnica do gaúcho não obedece às fronteiras nacionais, tampouco o faz um bioma). A descrição de como se dá essa inserção, passo a passo, e os desafios pelos quais a antropóloga passa, os sentimentos gerados, trazem à sua descrição do trabalho de campo um caráter de atemporalidade que encontramos junto a mestres que mostram o caminho da etnografia enquanto forma de produção conjunta; que nos conduzem pelas vicissitudes do fazer etnográfico em campo. Não por nada, Leal carrega consigo uma genealogia acadêmica importante, ao ser a quarta geração de antropólogos "descendentes" diretamente de Bronislaw Malinowski - o que, relacionado ao mito de origem da etnografia, fala sobre o rigor ao redor dessa produção. As descrições que nos aproximam da autora e de seu campo, ainda que tão distantes no tempo, mantém a vitalidade do texto enquanto sempre atual para a Antropologia.

Sua estada em campo é sempre marcada pelo gênero e pela divisão do espaço social decorrente, o que refletiria também na maneira como acessa os significados da masculinidade no local e o espaço concedido à mulher nesse meio. Leal (2021) aponta como seus dados de pesquisa a respeito das mulheres são "escassos e fragmentários", e isso se relaciona com o fato de que a mulher é para os homens uma ausência. Ainda assim, são tecidas análises importantes sobre o processo de afastamento da mulher do campo e de desvalorização social desta e do seu trabalho. As mulheres saem do campo e passam a viver em pequenas vilas, locais onde não necessariamente permanecem, visto a força do êxodo para a cidade e sua comparativa maior familiaridade com o meio urbano - ainda que tampouco vá receber mais prestígio ao findar este deslocamento e nas 
novas tarefas a desempenhar. Dentro destas possibilidades de circulação que a mantém desvalorizada, o sistema simbólico feminino segue existindo à imagem do homem.

À ocasião da invenção de tradições operada pelo Movimento Tradicionalista Gaúcho (MTG), a partir dos anos 40 do século passado e buscando promover a cultura gaúcha nos meios urbanos, a mulher passa a receber um lugar e uma vestimenta específicos enquanto prenda, par do gaúcho, incluindo-as em danças e tornando essa figura costume. É interessante potencializar essa análise aqui considerando como este movimento operado pelo MTG ocorre especificamente no Rio Grande do Sul, sem ultrapassar a fronteira nacional que separa dos gauchos uruguaios e argentinos: observando de perto, nota-se que a invenção da tradição é usada para fortalecer um sentimento de nação, "reabilitando" a imagem regional que outrora fora vista enquanto negativa devido à guerra farroupilha perdida. O movimento que o MTG faz é um dentro dos muitos artifícios usados para reabilitar a imagem desta "Revolução", trazendo consigo um imaginário de ampla democracia pastoril (ZALLA; MENEGAT, 2011) que melhor posicionaria o estado em uma ordem hierárquica competitiva nacional. Para além disso, nesse processo de positivação da imagem do gaúcho, o que foi operado com a imagem da mulher em prol de uma constituição regionalista assume um caráter distinto (mas integrado) com as categorias raciais.

A especificidade do trabalho no estado sempre foi reconhecida por viajantes e cientistas que passaram pelo solo brasileiro e reconheceram as particularidades dos gaúchos enquanto grupo étnico - Darwin foi um dos primeiros a fazê-lo de forma documentada. A autora remonta que parte dessa particularidade passava diretamente pela questão do trabalho: enquanto no Brasil colônia a maior parte das sesmarias produzia no formato de monocultura com elevado uso de mão de obra de pessoas negras escravizadas, no Rio Grande do Sul (à época, Província de São Pedro) ocorria principalmente a criação de gado, que exigia em muitos casos menor número de trabalhadores do que a agricultura ${ }^{2}$. Estes trabalhadores eram compostos primeiramente por uma força de trabalho indígena e negra escravizada, e posteriormente também por imigrantes assalariados. O fato apontado por Leal (2021) é que essa era a mão de obra que transformava o animal do campo em mercadoria e começava a gerar riqueza para o proprietário rural. Devido às especificidades do trabalho com animais do campo, era considerado que este requeria menos intervenção humana no processo produtivo - e entendo que este argumento foi o mesmo que ajudaria a mistificar a relação da escravização na Província de São Pedro, criando a imagem de uma "democracia rural pampeana" e de escravização mais branda e o alijamento dos negros escravizados e indígenas do produto de seu trabalho, tanto material quanto simbolicamente, visto que nunca foram reconhecidos enquanto parte da história sulriograndense ou contribuintes para as riquezas produzidas. No que tange à temática da

\footnotetext{
${ }^{2}$ Ainda que isso não esteja dado, visto que o trabalho nas charqueadas sulinas, voltado à produção da carne seca para alimentação do mercado interno, explorava um número elevado de mão de obra de pessoas escravizadas, em diversas funções especializadas particularmente difíceis e periculosas.
} 
identidade social, tampouco são reconhecidos como sendo parte do que é o gaúcho, ao menos em se tratando do reconhecimento simbólico conferido pelo MTG. Assim, o processo de trabalho ao longo do tempo, reconstruído pela autora em sua tese, traz os prenúncios de como operaria a racialização no estado desde os tempos do Brasil colônia até uma análise contemporânea de forma conectada com a leitura de um gaúcho enquanto identidade social.

Visualizamos com certa nitidez como são preponderantes na constituição da identidade gaúcha ideais masculinos de honra, dignidade e hierarquia, bem como o uso da força física para trabalhar no campo: "O gaúcho, em seu cavalo, sozinho no campo aberto, aparentemente sem limites no horizonte, tem o sentimento de domínio sobre o mundo ao seu redor. Ele celebra cotidianamente seu próprio corpo, sua força, sua virilidade" (p.333). Dois fenômenos são evocados pela autora para demonstrar em maior minúcia como tais aspectos se embrenham no cotidiano: as brigas de galos e o suicídio. A briga de galos, evento organizado por homens e para homens (e sendo a antropóloga a única figura feminina ali presente), celebram abundantes signos de masculinidade no embate ritualístico. Mesmo o galo que sofre, que perde, pode ter sua honra salva pela forma que se portar frente ao sofrimento (e, simbolicamente, portar-se feito galinha é razão de piada e significa a perda de tal dignidade - o afeminar-se remetendo à polaridade negativamente valorada do feminino). O foco (como já declarado em poemas e canções sobre este evento social) não é necessariamente ganhar, mas lutar sem submeter-se, em uma metáfora que remete aos ideais da identidade social do gaúcho e demonstra a proximidade do gaúcho com a morte.

Essa proximidade é cotidiana, da lida com o campo e com os animais; da necessidade de deixar morrer e matar, quando necessário, mesmo que se trate do vínculo afetivo duradouro com um velho cavalo. Da mesma forma que o animal perde a capacidade de exercer sua função, o homem passa pelo mesmo processo ao perder os atributos físicos necessários para ser um peão campeiro e permanecer na estância. É nesse contexto que o suicídio se torna uma alternativa honrosa, justa e correta, evocando os mesmos símbolos de masculinidade e sendo um fato social rememorado frequentemente nas conversas do cotidiano. Para o gaúcho, viver significa não temer a morte, e tem um caráter de domínio sobre a natureza ao redor - o que implica um domínio sobre a própria vida. Seu suicídio também é simbólico: depois de passar a vida laçando animais no campo, quando começa a perder a disputa com estes ele laça a si próprio, enforcando-se como "o último animal a ser domado" (p.302). Cabe apontar como a narrativa honrosa do suicídio masculino não confere os mesmos significados às tentativas de suicídio femininas, que são vistas com o riso do fracasso e da motivação pela espera de um homem que não chegaria.

É interessante observar como parte da análise da autora a respeito da briga de galos e do suicídio se pauta nas premissas do estruturalismo, especialmente em voga na época, estabelecendo relações dicotômicas para interpretar os eventos. Na briga de galos, por exemplo, "centro" e 
Espaço Ameríndio

"periferia" tornam-se princípios organizadores para pensar o galo e o homem, bem como a perene dicotomia "natureza" e "cultura", organizada em um quadro classificatório (p.281). Analiticamente, este recurso hoje parece um pouco datado, agrega pouco à construção da etnografia e parece um tanto quanto mecânica e rígida frente à vivacidade trazida na análise que a autora tece ao longo de sua tese.

Em vias de conclusão, a autora Ondina Fachel Leal entrega neste livro colaborações para que pensemos o campo antropológico amplamente, mesmo trinta anos depois do momento histórico no qual foi escrito. Sua relevância segue sendo reatualizada seja em termos metodológicos e etnográficos, ou pelas temáticas levantadas ao pensar a identidade social do gaúcho, como a central questão da masculinidade. 
Espaço Ameríndio

\section{Referências bibliográficas}

LEAL, Ondina Fachel. Do diário de campo: os percursos da descoberta do ser gaúcho, do ser homem (e do ser mulher). In: GONZAGA, Sergius; FISCHER, Luís Augusto. Nós, os gaúchos. Porto Alegre: Editora da Universidade - UFRGS, 1992.

ZALLA, Jocelito; MENEGAT, Carla. História e memória da Revolução Farroupilha: breve genealogia do mito. Revista Brasileira de História, v. 31, p. 49-70, 2011.

Recebido em: 29/11/2021 * Aprovado em: 01/12/2021 * Publicado em: 23/12/2021 